\title{
Electrophysiology of motor pathways for sphincter control in multiple sclerosis
}

\author{
S E Mathers, D A Ingram, M Swash
}

\begin{abstract}
The central and peripheral motor pathways serving striated sphincter muscle function were studied using cortical and lumbar transcutaneous electrical stimulation, pudendal nerve stimulation and sphincter electromyography in 23 patients with multiple sclerosis (MS), and sphincter disturbance, including incontinence of urine or faeces, urinary voiding dysfunction, or constipation. The central motor conduction time was significantly increased in the MS group compared to controls $(p<0.05)$. Damage to both the upper and lower motor neuron pathways can contribute to sphincter disturbance in MS. The latter may be due to coexisting pathology or to involvement of the conus medullaris by MS.
\end{abstract}

Abnormalities of sphincter function are common, socially disabling features of multiple sclerosis (MS). Bladder dysfunction occurs in up to $80 \%$ of cases and may be the presenting complaint. The severity of bladder symptoms has been correlated with the degree of corticospinal tract involvement. ${ }^{1}$ Faecal incontinence is a less frequent symptom, probably because constipation is so common in MS. Nonetheless, these symptoms are relatively rarely expressed in neurological consultation. Swash $e t a l^{2}$ found faecal incontinence a problem in patients with MS, and noted that it seemed related, in part, to chronic partial denervation of the striated anorectal sphincter muscles, associated with childbirth induced damage to the pudendal nerves. Colonic motility may also be impaired in MS with slowing of gut transit ${ }^{3}$ and absent post prandial colonic motor responses. ${ }^{4}$

The afferent and efferent nerve pathways serving micturition and defaecation were shown by Nathan and Smith to lie in the lateral columns throughout the length of the human spinal cord. ${ }^{5-7}$ Autoradiographic tracing techniques have delineated motor pathways in primates ${ }^{8}$ extending from the motor cortex to synapse with neurons in the Onuf's nucleus ${ }^{9}$ in the anterior horn of the sacral spinal cord segments, which innervate the striated sphincter muscles. That the central motor pathways to the sphincteric sacral motor neurons in humans conduct at velocities comparable to other corticospinal tract fibres has been shown using transcortical and spinal electrical stimulation. ${ }^{10}$
Slowing of conduction in these spinal pathways can also be detected in specific disease states associated with sphincter disturbance, such as multiple sclerosis and radiation myelopathy. ${ }^{11}$ The lower motor neuron pathway to the striated sphincter musculature has been extensively studied, in incontinent patients, using translumbar electrical stimulation, ${ }^{12}$ pudendal nerve stimulation ${ }^{13}$ and striated sphincter electromyography. ${ }^{14}{ }^{15}$ Both urinary and faecal incontinence have been correlated with damage to these sphincter lower motor neuron pathways, at proximal and distal sites, using these electrophysiological techniques.

The neural lesions underlying sphincter disturbance in MS are incompletely understood, and difficult to define clinically. Yet such information is important for the design of treatment and in assessing its effects. We have addressed this problem in an electrophysiological investigation of the central and peripheral motor nerve pathways to the striated sphincter musculature in a group of 23 patients with multiple sclerosis and sphincter disturbance.

\section{Patients}

Twenty three patients with clinically definite $M S^{16}$ and symptoms of sphincter dysfunction were recruited from the neurology service of The London Hospital, and through the outpatient practice of The Sir Alan Park's Physiology Unit, St Mark's Hospital, London. A full general and neurological clinical assessment was made in each patient. The clinical data are shown in table 1 . Six neurologically normal subjects acted as controls for central motor conduction time evaluation. These six patients had been admitted to hospital for surgical assessment of gastroenterological problems not associated with incontinence. All patients and controls gave their informed consent to the studies, which were approved by the Ethical Committees of both hospitals.

\section{Methods}

The electrophysiological studies were designed to assess the integrity of the corticospinal and sacral motor nerve pathways to the striated sphincter musculature. Anal manometry was performed using a station/pull-through technique to quantify resting anal pressure (mainly a function of the smooth muscle internal anal sphincter) and maximum squeeze pressure 
Table 1 Clinical features of MS patients

\begin{tabular}{|c|c|c|c|c|c|c|c|}
\hline $\begin{array}{l}\text { Case } \\
\text { No }\end{array}$ & $\begin{array}{l}\text { Age } \\
(y r s)\end{array}$ & Sex & Parity & $\begin{array}{l}\text { Kurtzke } \\
\text { scale }\end{array}$ & $\begin{array}{l}\text { Pyramidal } \\
\text { signs } \\
\text { (legs) }\end{array}$ & $\begin{array}{l}\text { Saddle } \\
\text { sensation }\end{array}$ & Sphincter disturbance \\
\hline 1 & 54 & F & 1 & 4 & + & $\mathbf{N}$ & UI intractable constipation \\
\hline 2 & 62 & $\mathrm{~F}$ & 2 & 5 & + & $\mathrm{N}$ & Voiding dysfunction, intractable constipation \\
\hline 3 & 51 & $\mathbf{F}$ & 1 & 6 & +++ & ABN & Occasional DI intractable constipation \\
\hline 4 & 48 & $\mathbf{F}$ & 3 & 7 & $++t$ & $\mathrm{~N}$ & DI urinary hesitancy \\
\hline 5 & 45 & $\mathrm{~F}$ & 0 & 7 & +++ & $\mathrm{N}$ & UI mild constipation \\
\hline 6 & 52 & F & 4 & 5 & + & $\mathrm{ABN}$ & DI urinary hesitancy (lumbar disc prolapse) \\
\hline 7 & 63 & $\mathbf{F}$ & 1 & 7 & +++ & $\mathbf{N}$ & UR UI mild constipation \\
\hline 8 & 32 & F & 1 & 5 & + & $\mathbf{N}$ & DI urinary hesitancy mild constipation \\
\hline 9 & 30 & F & 0 & 8 & $++t$ & $\mathbf{N}$ & DI \\
\hline 10 & 61 & F & 2 & 2 & + & $\mathrm{N}$ & Urinary urgency, anal pain \\
\hline 11 & 49 & $\mathrm{~F}$ & $\overline{3}$ & 8 & $+t+$ & $\mathrm{N}$ & UR constipation \\
\hline 12 & 37 & $\mathbf{F}$ & 3 & 5 & + & $\mathbf{N}$ & DI mild hesitancy and constipation \\
\hline 13 & 42 & $\mathbf{F}$ & 0 & 2 & + & $\mathbf{N}$ & UI mild hesitancy and constipation \\
\hline 14 & 39 & $\mathbf{F}$ & 3 & 5 & + & ABN & DI mild hesitancy (lumbar disc prolapse) \\
\hline 15 & 45 & M & & 5 & $+t$ & $\mathbf{N}$ & DI mild hesitancy \\
\hline 16 & 46 & M & & 5 & + & $\mathbf{N}$ & DI mild hesitancy (lumbar canal stenosis) \\
\hline 17 & 20 & $\mathbf{M}$ & & 2 & + & $\mathrm{N}$ & Urinary voiding dysfunction mild constipation \\
\hline 18 & 26 & M & & 5 & + & ABN & DI mild hesitancy (diabetes mellitus) \\
\hline 19 & 26 & M & & 7 & +++ & & FI ileal conduit for UR/UI \\
\hline 20 & 36 & M & & 5 & ++ & & Urinary urgency \\
\hline 21 & 33 & $\mathbf{M}$ & & 5 & 0 & ABN & DI mild constipation \\
\hline 22 & 39 & $\mathbf{M}$ & & 7 & $++t$ & ABN & Intractable constipation \\
\hline 23 & 47 & $\mathbf{M}$ & & 8 & +++ & ABN & DI intractable constipation \\
\hline
\end{tabular}

Kurtzke Disability Scale. ${ }^{31}$

Pyramidal signs in lower limbs: + mild tone and/or reflex changes without weakness; ++ spastic paraparesis causing significant gait disturbance; +++ disabling weakness and spasticity; wheelchair dependent.

Saddle sensation: $\mathrm{N}$-normal; ABN-abnormal.

UI-urinary incontinence; FI-faecal incontinence; DI-double incontinence; UR-urinary retention. Other relevant diagnoses are shown in brackets.

(reflecting voluntary activity in the striated external anal sphincter muscle). ${ }^{17} 18$

\section{CORTICAL STIMULATION}

Following the technique described by Merton and Morton, ${ }^{10}$ the motor cortex was excited transcutaneously using a Digitimer D180 electrical stimulator, which provides single capacitor discharges up to a maximum output of $750 \mathrm{~V}$ and decaying over $50 \mathrm{us}$. Two $1 \mathrm{~cm}$ diameter, saline-soaked pad electrodes were placed on the scalp in the median sagittal plane with the anode over the vertex and the cathode $5 \mathrm{~cm}$ anteriorly. The earth electrode was strapped to the patient's upper thigh. The cortex was stimulated with the patient lying in the flexed left-lateral position, and the motor response facilitated by asking the patient to weakly contract the muscle under study. Evoked motor potentials were recorded from the urinary striated sphincter muscle (USSM) by a catheter-mounted bipolar ring electrode (Dantec 21L11). Simultaneously, recordings were made from the puborectalis (PR) or external anal sphincter (EAS) muscles using glove or anal plug mounted surface bipolar electrodes, respectively. Stimulus intensity was adjusted to ensure supramaximal stimulation and the shortest, reproducible latency measured. Urinary catheterisation was not carried out in patients without urinary symptoms or where there was existing urinary infection. A past history of epilepsy was considered a contraindication to electrical cortical stimulation.

TRANSLUMBAR CAUDA EQUINA STIMULATION

Using the stimulating and recording apparatus described above, transcutaneous spinal stimulation was performed with the anode at the $\mathrm{Ll}$ lumbar level and the cathode $5 \mathrm{~cm}$ cranially in the midline. The shortest L1 spinal motor latencies to the striated sphincter muscles were recorded following supramaximal stimulation.
CENTRAL MOTOR CONDUCTION TIME (CMCT)

This was calculated by subtracting the L1 spinal latency from the cortical latency to the striated sphincter muscles.

PUDENDAL NERVE STIMULATION

The pudendal nerves in the pelvis were stimulated transrectally at the level of the sciatic notch using a glove mounted electrode array, (St Mark's Pudendal Electrode: Dantec 13L40), following the technique described previously. ${ }^{13}$ By recording the evoked motor response in the EAS or USS muscle, the distal motor latency was calculated for each pudendal (PNTML) and perineal (PerNTML) nerve, respectively.

SINGLE FIBRE ELECTROMYOGRAPHY (SFEMG)

The fibre density (FD) was calculated as the mean number of components in 20 consecutive motor unit potentials recorded using a single fibre needle electrode (Dantec 13K87) to sample both sides of the EAS muscle ring. Standard single fibre EMG filter settings were used. ${ }^{14}$

\section{CONTROL DATA}

Cortical and L1 spinal stimulation was performed, using the same procedures, in six neurologically normal patients, recording the surface evoked potential in the EAS muscle. The normal values for the other study parameters have previously been obtained in our laboratory, and these are given in table $4 .{ }^{18}$

\section{STATISTICAL METHODS}

The CMCT results in the patients and in control subjects were compared using Student's $t$ test. Results are expressed as mean, standard deviation.

\section{Results}

The clinical features of the 23 patients are 
Table 2 MS patients: electrophysiological results

\begin{tabular}{|c|c|c|c|c|c|c|c|c|c|c|}
\hline \multirow[b]{2}{*}{$\begin{array}{l}\text { Case } \\
\text { No }\end{array}$} & \multirow[b]{2}{*}{ Squeeze } & \multirow[b]{2}{*}{$\begin{array}{l}P N \\
T M L\end{array}$} & \multirow[b]{2}{*}{$\begin{array}{l}\text { PerN } \\
T M L\end{array}$} & \multirow[b]{2}{*}{$\begin{array}{l}F D \\
E A S\end{array}$} & \multicolumn{3}{|c|}{ Spinal latency (ms) } & \multicolumn{3}{|c|}{ Cortical latency (ms) } \\
\hline & & & & & $\begin{array}{l}\text { L1- } \\
\text { EAS }\end{array}$ & $\begin{array}{l}L 1- \\
P R\end{array}$ & $\stackrel{L 1-}{U S S M}$ & $\begin{array}{l}\text { Cortex } \\
-E A S\end{array}$ & $\begin{array}{l}\text { Cortex } \\
-P R\end{array}$ & $\begin{array}{l}\text { Cortex } \\
-U S S M\end{array}$ \\
\hline 1 & $\mathbf{N}$ & $\mathbf{N}$ & ABN & - & - & $4 \cdot 2$ & 5.0 & - & NR & 31.5 \\
\hline 2 & ABN & $\mathbf{N}$ & $\bar{T}$ & 1.5 & - & $6 \cdot 4$ & - & - & $31 \cdot 2$ & - \\
\hline 3 & $\mathbf{N}_{\mathrm{ARN}}$ & $\mathbf{N}$ & $\mathbf{N}$ & 1.7 & $\overline{N D}$ & $6 \cdot 8$ & $\overline{N D}$ & $\overline{N P}$ & NR & NR \\
\hline $\begin{array}{l}4 \\
5\end{array}$ & $\begin{array}{l}\mathrm{ABN} \\
\mathrm{ABN}\end{array}$ & $\mathbf{N}$ & $\mathbf{N}$ & $\begin{array}{l}2 \cdot 6 \\
3 \cdot 0\end{array}$ & NR & $\begin{array}{l}\text { NR } \\
9 \cdot 0\end{array}$ & $\begin{array}{l}\text { NR } \\
7 \cdot 7\end{array}$ & $\underline{\mathrm{NR}}$ & $\begin{array}{l}\text { NR } \\
\text { NR }\end{array}$ & $\begin{array}{l}\text { NR } \\
\text { NR }\end{array}$ \\
\hline 6 & $\mathrm{ABN}$ & $\mathbf{N}$ & ABN & - & - & 4.2 & 5.5 & - & NR & 17.6 \\
\hline 7 & $\mathrm{ABN}$ & $\mathbf{N}$ & $\mathbf{N}$ & 2.7 & - & - & - & - & & - \\
\hline 8 & $\mathbf{N}$ & ABN & NR & - & - & 6.5 & 6.0 & - & 32.5 & NR \\
\hline 19 & ABN & $\mathbf{N}$ & $\mathbf{N}$ & 1.7 & - & 6.0 & $5 \cdot 4$ & - & NR & NR \\
\hline 10 & $\mathbf{N}$ & $\mathbf{N}$ & - & $2 \cdot 0$ & $\overline{-10}$ & 6.7 & $\overline{5.3}$ & $\overline{N D}$ & NR & $\overline{330}$ \\
\hline $\begin{array}{l}11 \\
12\end{array}$ & ABN & $\overline{\mathrm{ABN}}$ & $\overline{\mathrm{ABN}}$ & 2.7 & $\begin{array}{l}4.9 \\
5.6\end{array}$ & - & $5 \cdot 3$ & NR & - & $32 \cdot 0$ \\
\hline 13 & $\mathbf{N}$ & $\mathrm{N}^{\mathrm{ABN}}$ & $\begin{array}{l}\mathrm{ABN} \\
\mathbf{N}\end{array}$ & $\begin{array}{l}2.3 \\
1.9\end{array}$ & $\begin{array}{l}5.6 \\
4.8\end{array}$ & 二 & $\begin{array}{l}4.4 \\
5 \cdot 0\end{array}$ & $\begin{array}{l}28.8 \\
30.8\end{array}$ & 二 & $\begin{array}{l}28.8 \\
32.8\end{array}$ \\
\hline 14 & $\mathbf{N}$ & ABN & $\mathbf{N}$ & 2.0 & 4.4 & 二 & 5.7 & 20.4 & $=$ & 20.0 \\
\hline 15 & $\mathbf{N}$ & $\mathbf{N}$ & $\mathbf{N}$ & - & NR & $\overline{-1}$ & NR & NR & $\bar{T}$ & NR \\
\hline 16 & $\mathbf{N}$ & $\mathbf{N}$ & $\mathbf{N}$ & $1 \cdot 6$ & $\overline{2}$ & 4.9 & $5 \cdot 4$ & $\overline{0}$ & NR & $29 \cdot 4$ \\
\hline 17 & $\mathbf{N}$ & $\bar{N}$ & $\bar{N}$ & $\overline{1.8}$ & 3.9 & $\overline{5.8}$ & $\overline{5.3}$ & $50 \cdot 4$ & $\overline{34.8}$ & $\overline{N P}$ \\
\hline $\begin{array}{l}18 \\
19\end{array}$ & $\begin{array}{l}\mathbf{N} \\
\mathbf{A B N}\end{array}$ & $\mathbf{N}$ & $\underline{N}$ & $\begin{array}{l}1.8 \\
1.5\end{array}$ & 二 & $\begin{array}{l}5.8 \\
4.9\end{array}$ & $5 \cdot 3$ & 二 & $34 \cdot 8$ & NR \\
\hline 20 & $\mathrm{ABN}$ & $\mathbf{N}$ & - & 1.7 & 6.0 & - & - & NR & - & - \\
\hline 21 & $\mathbf{N}$ & $\mathbf{N}$ & $\mathbf{N}$ & $2 \cdot 0$ & 3.6 & - & $4 \cdot 4$ & $\bar{x}$ & & $17 \cdot 8$ \\
\hline 22 & ABN & $\mathbf{N}$ & $\bar{x}$ & - & $5 \cdot 4$ & - & - & 34.0 & - & $\overline{N D}$ \\
\hline 23 & ABN & $\mathbf{N}$ & $\mathbf{N}$ & 1.8 & $5 \cdot 2$ & - & 6.0 & NR & - & NR \\
\hline
\end{tabular}

Squeeze - voluntary anal squeeze pressure during anal manometry. $\mathrm{N}$-normal; $\mathrm{ABN}$-abnormal (> mean $+2 \mathrm{SD}$ ); (-) -not tested; NR - no response. Other abbreviations, see text.

summarised in table 1 and the electrophysiological results appear in tables 2 and 3. Sphincter symptoms were not confined to the more severely disabled patients, but spread fairly evenly throughout the group.

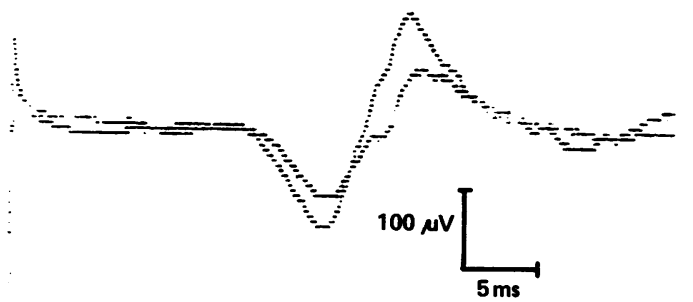

Figure 1 Cortical latency to EAS muscle in normal subject.

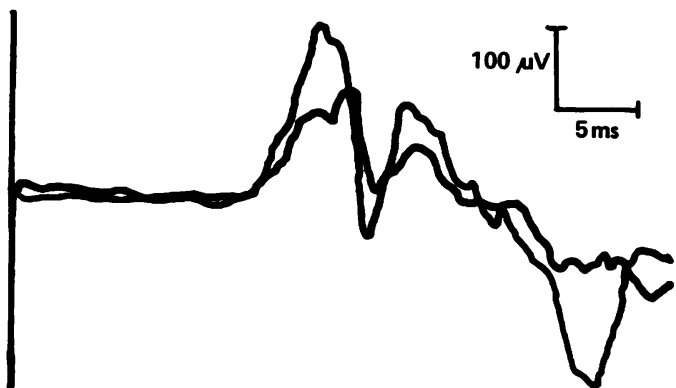

Figure 2 Normal cortical latency to USSM in MS patient.

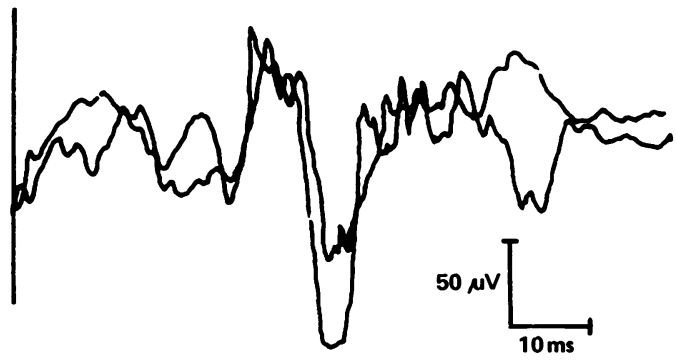

Figure 3 Abnormal cortical latency to EAS in MS patient.
ELECTROPHYSIOLOGICAL RESULTS

The CMCT to the striated anal sphincter muscle in control subjects was $15 \cdot 3+/-3 \cdot 5$ ms. All patients in the control group had recordable cortical latencies. CMCT to the sphincter sacral cord segments was determined in $13 \mathrm{MS}$ patients and no response could be recorded from any of the sphincter muscles in a further eight patients. In the MS patient group, the mean CMCT for the striated anal sphincter muscles (EAS + PR) was $27.5 \mathrm{~ms}$ and for USSM $21.2 \mathrm{~ms}$. The mean (SD) of the shortest CMCT value measured to any of the striated sphincter muscles in individual MS patients was $24.7(8.4) \mathrm{ms}$ ( $\mathrm{p}<0.05$ compared with control values). Cortical stimulation was not performed in two cases. Eleven of 13 patients in whom an evoked sphincter muscle response was present were still independently ambulant, compared to $0 / 8$ of those where the response was unobtainable. The severity of corticospinal tract involvement as assessed by

Table 3 Control patients: central motor conduction time

\begin{tabular}{llllll}
\hline Case Age & Sex & $\begin{array}{l}\text { Spinal } \\
\text { latency } \\
\text { L1-EAS } \\
(\text { ms })\end{array}$ & $\begin{array}{l}\text { Cortical } \\
\text { latency } \\
\text { Cortex-EAS } \\
(\text { ms })\end{array}$ & $\begin{array}{l}\text { CMCT-EAS } \\
\text { (ms) }\end{array}$ \\
\hline 1 & 37 & $\mathrm{~F}$ & $5 \cdot 2$ & $26 \cdot 4$ & $21 \cdot 2$ \\
2 & 33 & $\mathrm{~F}$ & $4 \cdot 8$ & $18 \cdot 2$ & $13 \cdot 4$ \\
3 & 20 & $\mathrm{M}$ & $4 \cdot 3$ & 19.8 & $15 \cdot 5$ \\
4 & 20 & $\mathrm{M}$ & $4 \cdot 4$ & $18 \cdot 4$ & $14 \cdot 0$ \\
5 & 43 & $\mathrm{M}$ & $4 \cdot 5$ & $22 \cdot 2$ & $17 \cdot 7$ \\
6 & 35 & $\mathrm{M}$ & $5 \cdot 1$ & $15 \cdot 2$ & $10 \cdot 1$ \\
\hline
\end{tabular}

$\mathrm{CMCT}-$ central motor conduction time $\underset{(\mathrm{ms}) \text {. }}{\text { Mean }}$

Table 4 Electrophysiological tests: normal data ${ }^{18}$

\begin{tabular}{ll}
\hline SFEMG & $1 \cdot 32(0 \cdot 1)(<30 \text { years })^{\star}$ \\
PNTML (ms) & $1 \cdot 5(0 \cdot 16)(<65$ years $)$ \\
PerNTML (ms) & $2 \cdot 0(0 \cdot 2)^{\star}$ \\
L1-EAS (ms) & $2 \cdot 4(0 \cdot 2)^{\star}$ \\
L1-PR (ms) & $5 \cdot 5(0 \cdot 4)^{\star}$ \\
L1-USSM (ms) & $4 \cdot 8(0 \cdot 4)^{\star}$ \\
\hline
\end{tabular}

${ }^{\star}$ Mean (SD). 
upper motor neuron signs in the lower limbs did not correlate well with the values obtained for CMCT to the sphincter muscles.

Sixteen ( 3 male, 13 female) patients had evidence of damage to the lower motor neuron pathways to the striated sphincter musculature, including the three patients with normal CMCT values: raised fibre density in EAS -10 patients (two male, eight female), increased L1 spinal latency-10 patients (two male, eight female), increased PNTML-three parous women, increased PerNTML-three parous women. Seven patients showed more than one abnormality. Possible reasons for these abnormalities other than MS were present in 12 cases (parity 10, lumbar intervertebral disc disease three, diabetes mellitus one).

CORRELATION BETWEEN

ELECTROPHYSIOLOGICAL FINDINGS AND

PATTERN OF SPHINCTER DISTURBANCE

1 Urinary incontinence

Seventeen patients had urinary urgency and incontinence ( 11 female, 6 male). Eight were parous women and all had some evidence of damage to the sphincter muscle lower motor neuron innervation, including five with slowing of distal motor conduction in the pudendal nerve or its perineal branch. Three nulliparous women and six men also suffered from urinary incontinence. None of these patients showed any distal pudendal nerve motor conduction slowing although the fibre density in the EAS muscle was elevated in 4/8. Fifteen of the 17 patients with urinary incontinence had cortical and spinal stimulation and CMCT was abnormal in 12. Three patients had CMCT to the striated sphincter muscles within the normal range: two parous women, and one male whose initial clinical presentation was consistent with a lesion of the conus medullaris.

\section{Urinary voiding dysfunction}

Fourteen patients complained of difficulty with voluntary bladder emptying. Nine (three male, six female) had mild and intermittent hesitancy of micturition associated with more prominent symptoms of urinary urgency and incontinence. Evidence of lower motor neuron damage was present in all six of these women (five parous) and one man. CMCT studies were abnormal in seven (five delayed, two absent).

Five patients had more significant urinary retention, requiring catheterisation in two cases and an ileal conduit in one. Two were independently ambulant and three wheelchair bound. They described less incontinence than those with occasional hesitancy, and tended to show less electrophysiological evidence of damage to the lower motor neuron pathway. Two parous women had a raised fibre density in the EAS muscle. CMCT was increased to one or both sphincter muscles in all three patients studied.

\section{Faecal incontinence}

Thirteen patients had recurring episodes of faecal incontinence (six male, seven female-one nulliparous). All had normal resting anal tone on manometry. Five had very poor or absent voluntary anal sphincter contraction (two male, three female). CMCT studies recording from the striated anal sphincter muscles were abnormal in 10 cases (delayed three, absent seven). Eight patients (three male, five female) had evidence of damage to lower motor neuron pathways to the striated anal sphincter muscles in addition to abnormal central motor conduction.

\section{Constipation}

Thirteen patients had experienced a change in bowel habit since the onset of MS. Eight patients had a mild and variable tendency to constipation which was responsive to dietary measures or occasional oral laxative medication. None of these patients described chronic straining at stool. As a group they tended to have more evidence of lower motor neuron pathway damage to the striated anal sphincter muscles (raised fibre density in EAS- 6/6, increased PNTML-2/7, and increased spinal latency to EAS or PR-2/7) than those with severe constipation. CMCT was increased in five, absent in one and normal in one case.

The five other cases (two male, three parous women) had intractable constipation, usually accompanied by tenesmus, chronic straining and abdominal bloating. Three patients had been admitted to hospital because of obstructive bowel symptoms. Two were freely ambulant, two had a marked spastic paraparesis and could walk only a few steps with assistance and one was wheelchair dependent. Voluntary anal squeeze pressure was reduced in three cases, and all showed paradoxical increase in striated sphincter muscle activity instead of the normal inhibition when asked to perform a defaecation strain. ${ }^{19}$

This disorganisation of the normal pattern of muscle activity during defaecation straining was confirmed in three cases by defaecating proctography. ${ }^{20}$ Paradoxical upward movement of the pelvic floor was seen, consistent with muscle contraction, and poor opening of the anal canal obstructed the expulsion of barium from the rectum. Four of these five patients described alteration of bladder or anorectal sensation, and three had subjective alteration of pinprick sensation in the saddle area. All five had abnormal or absent cortical latencies to the sphincter muscles. Pudendal latencies were normal in all five patients.

\section{Discussion}

The pathways for neural control of the bladder and bowel sphincter mechanisms traverse the whole neuraxis, and are therefore frequently involved in a multifocal condition such as MS. Our results show that conduction in the upper motor neuron pathways to the Onuf's nucleus is usually, but not always, slowed in patients with MS and sphincter disturbance. CMCT measurements were not specific for the pattern of sphincter disturbance with incontinence versus voiding dysfunction. Since the electrode placement used for transcortical stimulation probably excite the parasagittal motor cortex 
bilaterally, and the recording electrodes are arranged bilaterally as catheter-mounted ring electrodes, or anal plug electrodes, the latency of the motor response in the striated sphincter muscle will reflect conduction in the fastest of the preserved corticospinal fibres from both hemispheres. Therefore, unilateral or lesser degrees of damage to these pathways will not easily be detected by this technique. It seems likely that our patients with sphincter symptoms and abnormal cortical motor latencies to the sphincter muscles, had bilateral lesions affecting these pathways, though not necessarily at the same level on each side.

Although the CMCT values to the sphincteric sacral segments in the patient group are significantly greater than in the controls, most abnormal values did not show the two to three fold increase which has been reported for other skeletal muscles studied in MS patients. ${ }^{21-23}$ This and the number of unrecordable responses in our series probably reflects the greater difficulty in recording low amplitude, dispersed potentials from the relatively small striated sphincter muscles, especially in the presence of lower motor pathway dysfunction and denervation atrophy. It also suggests that sphincter motor control may be significantly disrupted by relatively minor changes in motor pathway conduction. When repeated stimulation is required to establish the latency of small, dispersed motor potentials, transcutaneous magnetic stimulation may be better tolerated by patients. ${ }^{23}$ However, electrical excitation allows greater localisation of the stimulus which is important for the interpretation of spinal stimulation results.

Translumbar spinal stimulation at the level of the conus medullaris probably excites the proximal motor axons rather than the nerve cell bodies, but the precise location is unresolved. Maertens de Noordhout et al ${ }^{24}$ localised the point of activation to within $3.5 \mathrm{~cm}$ of the cell body but commented that it may be as proximal as the axon hillock. The peripheral component in the CMCT is therefore likely to be small.

Lower motor neuron abnormalities wert frequently present in sphincter pathways. Most commonly this was found in association with parity, as was noted by Swash et al. ${ }^{2}$ Only parous women patients with MS had increased terminal motor latencies in the pudendal nerve or its perineal branch. Although theoretically, any lower motor neuron lesion causing significant Wallerian degeneration within the pudendal nerve could result in an increased terminal motor latency, injury to these nerves during childbirth is the most likely pathogenesis of these abnormalities. Although six out of eight parous MS patients tested had a raised fibre density in the EAS muscle on single fibre EMG, this abnormality was also found in one male and two nulliparous female patients with no known coexisting lower motor neuron pathology. Involvement of the conus medullaris by MS, with secondary axonal atrophy in the sphincter motor neurons may best account for these changes in these three patients, and could contribute to the lower motor neuron disturbance found in the others.
From the example of patients with complete spinal cord transection, it is clear that suprasacral control centres are important for the voluntary initiation and deferment of micturition and defaecation. Without this input, the anorectum and bladder tend to function automatically, emptying reflexly in response to filling or to cutaneous stimuli applied within the sacral dermatomes. Many patients with spinal cord disease have difficulty establishing even this reflex bladder emptying because of vesico-urethral dysfunction, especially detrusor-sphincter dyssynergia. ${ }^{25}$ This suggests failure of integration between the visceral and somatic motor systems once the sacral cord is isolated from higher control centres. In the same way, striated pelvic floor muscle dysfunction can contribute to constipation in MS patients by causing a functional obstruction at the pelvic outlet. The five patients in our series with intractable constipation all showed a paradoxical increase in striated sphincter muscle activity on attempted defaecation straining. Paradoxical striated pelvic floor muscle contraction indicates a disturbance of the normal pattern of recruitment and inhibition of striated muscle during the voluntary motor task of defaecation straining. ${ }^{26}$ It is uncertain whether this represents dysfunction in the descending pyramidal or non-pyramidal influences on segmental spinal activity. Patients with severe urinary and faecal voiding dysfunction had, in general, less evidence of disruption to lower motor neuron innervation of sphincter muscles than patients with mild voiding disorders associated with incontinence. However, without the use of urodynamic studies, it is not possible to determine the relative contributions of detrusor hyperreflexia and sphincter muscle weakness to the pathogenesis of urinary incontinence in each case. It is presumed that patients with paradoxical anal sphincter muscle activity during defaecation straining are more likely to achieve some degree of evacuation when the sphincter muscle is weakened by partial denervation. Indeed sphincterotomy is the usual surgical management of idiopathic voiding disorders. ${ }^{27}$

These electrophysiological investigations allow the identification of upper and lower motor neuron components to the sphincter disturbance in MS. Increased CMCT values to the striated sphincter muscles can signal the presence of an upper motor neuron abnormality where MS coexists with other pathologies such as diabetes mellitus or lumbar intervertebral disc prolapse (Cases 18 and 16). Lower motor neuron dysfunction may also be due to involvement of the conus medullaris by $\mathrm{MS},{ }^{28}$ and our results reaffirm the previously reported contribution of distal pudendal nerve damage to incontinence in parous women with $\mathrm{MS}^{2}{ }^{2}$ Pelvic floor surgery can ameliorate incontinence due to weakened, partially denervated pelvic sphincter muscles ${ }^{29}$ and may be appropriate in some incontinent patients with MS. However, coexisting voiding or defaecatory dysfunction may worsen if the pelvic floor mechanism is made functionally more competent in this way. 
Although we have demonstrated motor pathway abnormalities in all our patients with MS and sphincter disturbance, other neuronal systems with relevance to sphincter control may also be affected. We know from animal studies that the sacral parasympathetic neurons and the cells of Onuf's nucleus receive dual innervation from higher autonomic and somatic neural centres which may be an anatomical substrate for functional integration. ${ }^{30}$ Nathan and Smith showed that spinal pathways for both conscious and unconscious vesicourethral and anorectal control lie close together in the spinal cord..$^{5-7}$ Nevertheless, we cannot directly infer autonomic nervous system involvement from our studies of somatic nerve pathways. Impairment of frontal lobe function and involvement of sensory and extrapyramidal pathways also contribute to the complexity of this problem and may limit the analysis of electrophysiological studies of sphincter symptoms in patients with MS.

We thank our colleagues at The London and St Mark's Hospitals and the patients for their cooperation in the study, and Hospital Research Foundation.

1 Miller H, Simpson CA, Yeates WK. Bladder dysfunction in multiple sclerosis. Br Med J 1965;1:1265.

2 Swash M, Snooks SJ, Chalmers DHK. Parity as a factor in incontinence in multiple sclerosis. Arch Neurol 1987 44:504-8.

3 Weber J, Grise P, Roquebert M, Hellot MF, Mihout B, Samson M, Beuret-Blanquart F, Pasquis P, Denis $P$. Samson $M$, Beuret-Blanquart $F$, Pasquis $P$, Denis $P$. Radiopaque markers transit and anal manometry in 16 patients with multiple sclerosis and uring

4 Glick ME, Meshkinpour H, Haldeman S, Bhatia NN, Bradley WE. Colonic dysfunction in multiple sclerosis. Gastroenterology 1982;83:1002-7.

5 Nathan PW, Smith MC. The centripetal pathway from the bladder and urethra within the spinal cord. $J$ Neurol Neurosurg Psychiatry 1951;14:262-80.

6 Nathan PW, Smith MC. Spinal pathways subserving defaecation and sensation from the lower bowel. $J$ Neurol Neurosurg Psychiatry 1953;16:245-56.

7 Nathan PW, Smith MC. The centrifugal pathways for micturition within the spinal cord. I Neurol Neurosurg Psychiatry 1958;21:177-89.

8 Nakagawa S. Onufs nucleus of the sacral cord in a South American monkey (Saimiri): its location and bilateral American monkey (Saimiri): its location and bilateral cortical

9 Onuf (Onufrowicz) B. On the arrangement and function of the cell groups in the sacral region of the spinal cord. Arch Neurol Psychopathol 1900;3:387-411.

10 Merton PA, Hill DK, Morton HB, Marsden CD. Scope of a technique for electrical stimulation of human brain, spinal cord and muscle. Lancet 1982;ii:597-600.

11 Snooks SJ, Swash M. Motor conduction velocity in the human spinal cord: slowed conduction in multiple human spinal cord: slowed conduction in multiple Psychiatry 1985;48:1135-9.

12 Swash M, Snooks SJ. Slowed motor conduction in lumbosacral nerve roots in cauda equina lesions: a new diagnostic technique. J Neurol Neurosurg Psychiatry 1986; 49:808-16.

13 Kiff ES, Swash M. Slowed conduction in the pudendal nerves in idiopathic (neurogenic) faecal incontinence. $\mathrm{Br} J$ Surg 1984;71:614-16.

14 Neill ME, Swash M. Increased motor unit fibre density in the external anal sphincter muscle in anorectal incontinence: a single fibre EMG study. $J$ Neurol Neurosurg Psychiatry 1980;43:343-7.

15 Fowler CJ, Kirby RS, Harrison MJG, Milroy EJG, TurnerWarwick $R$. Individual motor unit analysis in the Warwick R. Individual motor unit analysis in the diagnosis of disorders of urethral inn
Neurosurg Psychiatry 1984;47:637-41.

16 McAlpine D, Lumsden CE, Acheson ED. Multiple Sclerosis: a re-appraisal. Edinburgh: Churchill Livingstone, 1972:225.

17 Neill ME, Parks AG, Swash M. Physiological studies of the pelvic floor in idiopathic faecal incontinence and rectal prolapse. Br J Surg 1981;68:531-6.

18 Henry MM, Snooks SJ, Barnes PRH, Swash M. Investigation of disorders of the anorectum and colon. Ann Roy Coll Surg Eng 1985;67:355-60.

19 Floyd WF, Walls EW. Electromyography of the sphincter ani externus in man. $J$ Physiol (Lond) 1953;122:599-609.

20 Bartram CI, Turnbull GK, Lennard-Jones JE. Evacuation proctography: an investigation of rectal expulsion in 20 proctography: an investigation of rectal expulsion in 20 Radiol 1987;13:72-80.

21 Cowan JMA, Rothwell JC, Dick JPR, Thompson PD, Day BL, Marsden CD. Abnormalities in central motor pathway conduction in multiple sclerosis. Lancet 1984;ii: $304-7$.

22 Mills KR, Murray MF. Corticospinal tract conduction in multiple sclerosis. Ann Neurol 1985;18:601-5.

23 Ingram DA, Thompson A, Swash M. Central motor conduction in multiple sclerosis: evaluation of abnormalities brain. J Neurol Neurosurg Psychiatry 1988;51:487-94.

24 Maertens de Noordhout A, Rothwell JC, Thompson PD, Day BL, Marsden CD. Percutaneous electrical stimulation of lumbosacral roots in man. J Neurol Neurosurg Psychiatry 1988;51:174-81.

25 Blaivas JG. The neurophysiology of micturition: a clinical study of 550 patients. J Urol 1982;127:958-63.

26 Mathers SE, Kempster PA, Swash M, Lees AJ. Constipation and paradoxical puborectalis contraction in anismus and Parkinson's disease: a dystonic phenomenon? J Neurol Neurosurg Psychiatry 1988;51:1503-7.

27 Kamm MA, Hawley PR, Lennard-Jones JE. Lateral division of the puborectalis muscle in the management of severe constipation. Br J Surg 1988;75:661-3.

28 Taylor MC, Bradley WE, Bhatia N, Glick M, Haldeman S. The conus demyelination syndrome in multiple sclerosis. Acta Neurol Scand 1984;69:80-9.

29 Henry MM, Simson JNL. Results of postanal repair: a retrospective study. Br J Surg 1985;72 (Suppl):S17-19.

30 Holstege G, Tan J. Supraspinal control of motoneurons innervating the striated muscles of the pelvic floor including urethral and anal sphincters in the cat. Brain ing urethral and

31 Kurtze JF. Further notes on disability evaluation in multiple sclerosis, with scale modifications. Neurology 1965;15:654-61. 